Military Technical College

Kobry El-Kobbah,

Cairo, Egypt

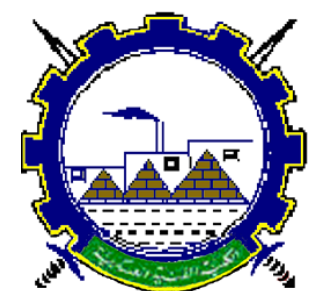

I.C.E.E.2018
9는 International Conference

on

Chemical \& Environmental

Engineering

3-5 April 2018

SAN-2

\title{
Composite and nano composite coatings for improving physical, mechanical and chemical properties
}

By

\author{
Z. Abdel Hamid
}

\begin{abstract}
Composite or nanocomposite coatings, a new branch of deposition that possess unique physical and mechanical properties are formed by mixing two or more dissimilar materials at the micron or nanoscale. Composites are used when a combination of properties is required that cannot be found in a single material. The properties of composite depend upon not only the individual components used but also the morphology and the interfacial characteristics. The nancomposites can exhibit enhanced mechanical, electrical, magnetic, and/or optical properties compared with their conventional micron-scale (or larger) counterparts. Nanocomposite materials and coatings therefore offer enormous potential for new applications including: aerospace, automotive, electronics, biomedical implants, non-linear optics, mechanically reinforced lightweight materials, sensors, nano-wires, batteries, bioceramics, energy conversion and many others. This work presents the scientific framework for the advances in the composite and nanocomposite coatings research, including fundamental composition/property relationships, fabricating techniques, and applications. Additionally, the co-deposition of various metallic matrices with a great variety of sized powders from hard carbides, oxides, and ceramics are discussed.
\end{abstract}

Corrosion Control and Surface Protection Lab. Central Metallurgical R \& D Institute, Cairo, Egypt forzeinab@yahoo.com 